\title{
Effect of the Coating Thickness to Ti(C、N)/ Ni60A Composite Coating by Ultrasonic-assisted Argon-arc Clad Injection
}

\author{
Ning Zhang ${ }^{1, a}$, Sun Han ${ }^{1, b}$, Fu Jian ${ }^{1, c}$, Zhang Chunhong ${ }^{2, d}$ \\ ${ }^{1}$ Jiangsu Key Laboratory of Large Engineering Equipment Detection and Control, School of \\ Mechanical \& Electrical Engineering, Xuzhou Institute of Technology, Xuzhou, 221018, China \\ ${ }^{1}$ Department of Mechanical \& Electrical Engineering, Xuzhou Bioengineering Technical College, \\ Xuzhou, China \\ a sprningzn@126.com, b 904942057@qq.com, ${ }^{\text {c } 3057943595 @ q q . c o m, ~}{ }^{d}$ sprning@126.com
}

Keywords: argon-arc clad injection; ultrasonic-assisted; coating thickness; Ti(C, N) )/ Ni60A

Abstract. New ultrasonic-assisted argon-arc clad injection technology was adopted, and Ni60A was as cladding powder, TiC, TiN, WC, and Co powder as spraying powder, thus Q235 steel plate was strengthened with $\operatorname{Ti}(\mathrm{C} 、 \mathrm{~N})$ particle reinforced the nickel wear-resistant coating. The influence of the coating thickness to the organizational structure, the phase and composition, the reinforced phase, the hardness and wear resistance of the cladding layer was analysed by presetting different thickness of the surface coating. The results showed that for the secondary effects of acoustic cavitation and acoustic streaming produced by the high energy ultrasonic spreading in the molten pool, the wettability between the particles and the melt was improved, the reaction in situ was promoted, the strengthening phase dispersed, and the gas escaped easily. When the thickness of the coating is $0.8,1.2$ and $1.6 \mathrm{~mm}, 1.2 \mathrm{~mm}$ thicknesses of the specimen has a good appearance. The reinforced particulates distribute uniformly. The hardness is 7 times than that of the Q235 steel, and the wear resistance is 14.3 times than that of the steel matrix. The comprehensive performance is the best.

\section{Introduction}

With the rapid development of modern industrial technology, the surface properties of parts are considerably improved. In this experiment, a new type of ultrasonic-assisted argon-arc clad injection method was proposed, and a set of experimental apparatus was developed. The ultrasonic-assisted vibration device includes ultrasonic generator, transducer, horn and tool head. The maximum power of the generator is $800 \mathrm{~W}$, and the frequency is $20 \mathrm{KHz}$. Alloy powders were coated on the surface of the workpiece, injecting enhancement particles when argon-arc cladding, and supplemented by ultrasonic vibration. The high heat source of argon-arc can melt the particles in the molten pool, at the same time, the cavitation and acoustic streaming effect generated by ultrasonic vibration in the melt are used to improve the wetting of the particles and melt, promote nucleation, refine grain, enhance the dispersion of reinforcing particles in the melt, improve the escape of gas in molten pool. The $\mathrm{Ti}(\mathrm{C}, \mathrm{N})$ ceramic particles reinforced surface composite materials had good wear resistance, corrosion resistance, and excellent performance.

\section{Experimental materials and methods}

Experimental materials. In this experiment, Q235 steel plate is used as substrate material, and the size is $300 \mathrm{~mm} \times 50 \mathrm{~mm} \times 10 \mathrm{~mm}$. The cladding powder is chosen as Ni60 powders $(60 \sim 90 \mu \mathrm{m})$, spray powders for mixed $\mathrm{TiC}$ powders $(75 \sim 150 \mu \mathrm{m})$, TiN powders $(10 \sim 25 \mu \mathrm{m})$, WC powders $(40 \sim 50 \mu \mathrm{m})$, and Co powders $(60 \sim 90 \mu \mathrm{m})$. The composition ratio is TiC:TiN:WC:Co=10:10:2:1.

Experimental methods. Q235 steel plate with rust on the surface was burnished with the sand paper in advance, then was cleaned and unoiled respectively by acetone and absolute ethyl alcohol. Coating material was the Ni base self-fluxed Ni60A alloy powder, sodium silicate as binder, pressed with the small press with home-made mould, the thickness of sample $1 \#$ was $0.8 \mathrm{~mm}$, sample $2 \#$ was $1.2 \mathrm{~mm}$, and sample $3 \#$ was $1.6 \mathrm{~mm}$, then coated on Q235 steel plate. The specimens were coated well 
placed in ventilated place to dry naturally 24 hours, then put into the drying box heated to $70^{\circ} \mathrm{C}$ preheating for 1 hour first, and then heated to $150^{\circ} \mathrm{C}$ heat preservation and drying for 2 hours. Next the Ti $(\mathrm{C}, \mathrm{N})$ reinforced Ni60 matrix composite coating with different thickness was set by the ultrasonic-assisted argon-arc clad injection technology. The schematic diagram was shown in Fig.1.

The cladding process was that the welding current of $130 \mathrm{~A}$, argon flow of $12 \mathrm{~L} / \mathrm{min}$, cladding speed of $30 \mathrm{~mm} / \mathrm{min}$, the injection speed of $35 \mathrm{ml} / \mathrm{h}$, ultrasonic power of $800 \mathrm{~W}$. After cladding, remove the ultrasonic tool head, wait for the welding by natural cooling.

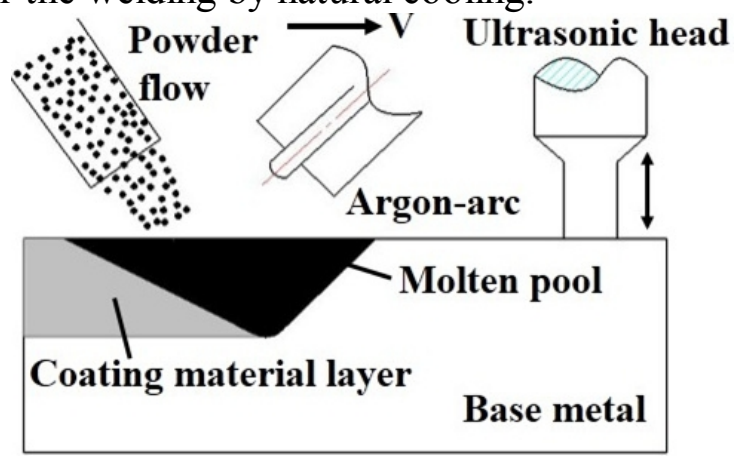

Fig.1 Schematic diagram of the ultrasonic-assisted argon-arc clad injection

The cross section of the cladding specimen was cutted by the linear cutting machine. Then the cladding profile was ground with metallographic sandpaper and polished on the polishing machine. The specimen after preparation was corroded, the substrate Q235 steel with 4\% nital, and the surfacing layer by a mixture of 20\% nitric acid and hydrofluoric acid (HF: HNO3 = 1:3) with the alcohol solution. The microstructure of cladding layer was observed by FEI Inspect S50 scanning electron microscope. The composition of the reinforcement particle on the fusion zone was analyzed by OXFORD X act/INCA 150 energy disperse spectroscopy, with HV - 1000 micro hardness tester measuring microhardness near the fusion zone, the SFT-2M pin disc friction and wear testing machine measuring the wear volume of matrix and cladding layer.

\section{Experimental results and discussion}

Microstructure of composite coating. The interface microstructure of the cladding layer for different thickness are shown in Fig.2. After the cladding, the sample profile shows obvious three block area, that are fusion region, bond zone, and base area. From Fig.2(a) it can be seen that the thickness of the cladding layer is relatively small for $0.8 \mathrm{~mm}$, so the dilution rate of the matrix region is relatively large, the enhanced phase particles generated less in the cladding layer, the combination between the cladding layer and the substrate is not very good. Fig.2(b) shows the thickness of the cladding layer of $1.2 \mathrm{~mm}$, he cladding layer has good quality, and no defects such as porosity, crack, and no welding. From Fig.2(c), the thickness of the cladding layer as $1.6 \mathrm{~mm}$, due to the thickness of the thick, there is a phenomenon of non penetration welding, some air holes are also appeared, so the combination of the cladding layer and the substrate is not closely related, which affects the performance of the cladding layer. 


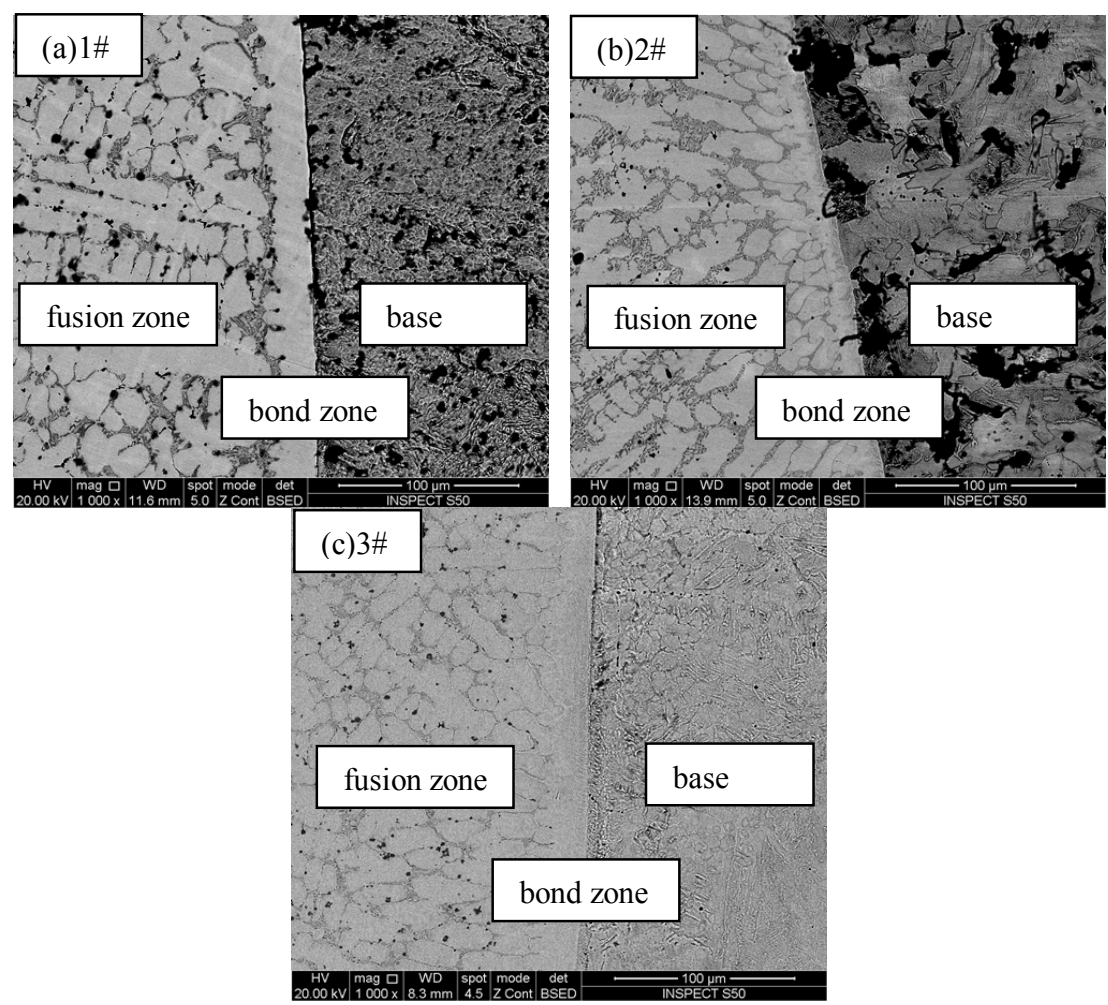

Fig.2 Metallographic structure of the composite coating

Organizational characteristics of composite coating. EDS point analysis of different regions of the $2 \#$ specimen cladding layer is shown in Fig.3. Point $\mathrm{A}$ is a quadrilateral block, which is $\mathrm{Ti}(\mathrm{C}, \mathrm{N})$; Point $\mathrm{B}$ is needle like reinforcing phase, which is $\mathrm{TiC}$ and $(\mathrm{Fe}, \mathrm{Ni})_{23} \mathrm{C}_{6}$; Point $\mathrm{C}$ is larger sheet phase, which is $\mathrm{Cr}_{23} \mathrm{C}_{6}$ and $\mathrm{Cr}_{7} \mathrm{C}_{3}$ mainly containing $\mathrm{Fe}$; Point $\mathrm{D}$ is composed of three elements for $\mathrm{C}$, Fe, and $\mathrm{Ni}$ elements, while solid dissolve small amount of $\mathrm{Ti}, \mathrm{Cr}$ and $\mathrm{W}$ elements.

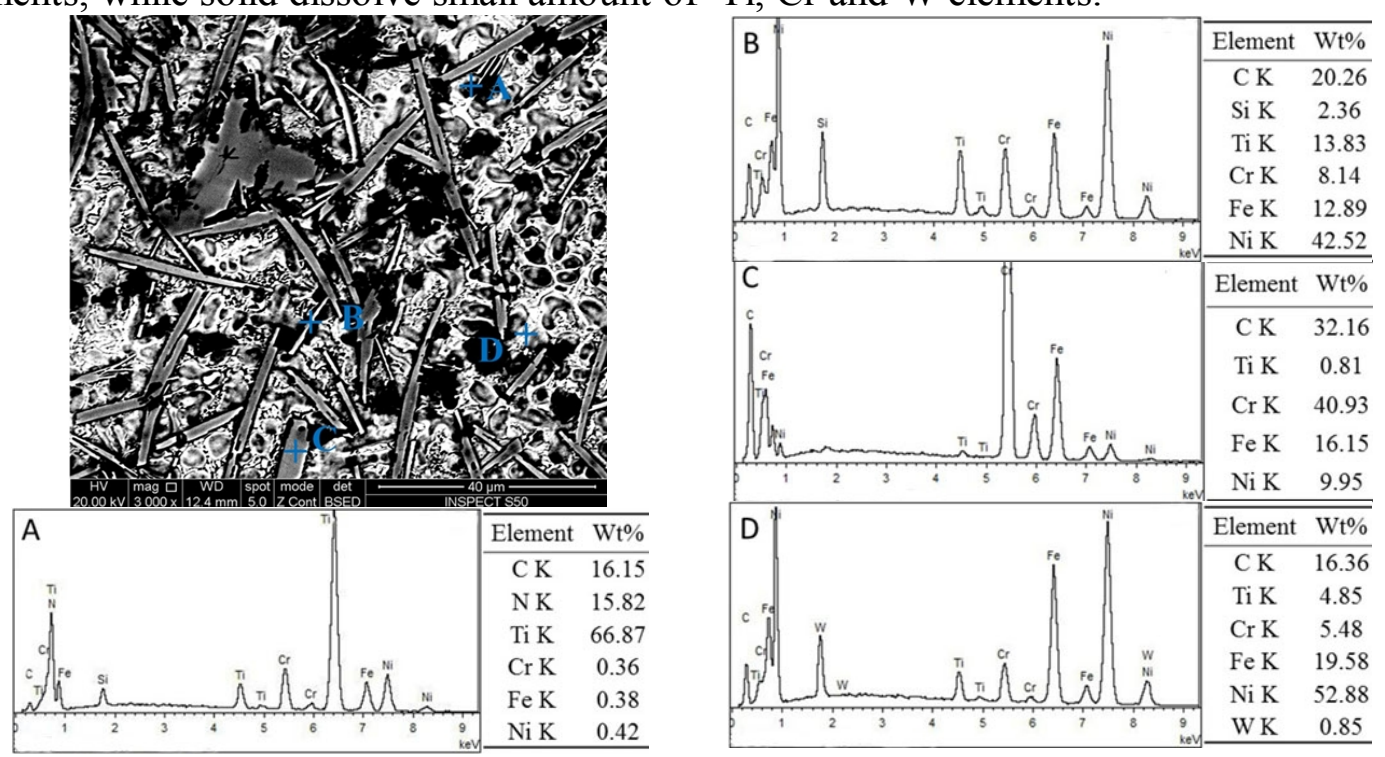

Fig.3 SEM photos of the cladding layer

Microhardness of composite coating. The microhardness distribution from surfacing to matrix of the cladding layer is shown in Fig.4. The figure demonstrates that the broken line increases first and then decreases. The hardness of cladding layer is higher, the hardness of sample $2 \#$ raise the highest about $1158.8 \mathrm{HV}$, sample $1 \#$ as $1114.6 \mathrm{HV}$ secondly, sample $3 \#$ as $1082.1 \mathrm{HV}$ at lowest. The microhardness of sample 2\# is 7 times than the matrix Q235. 


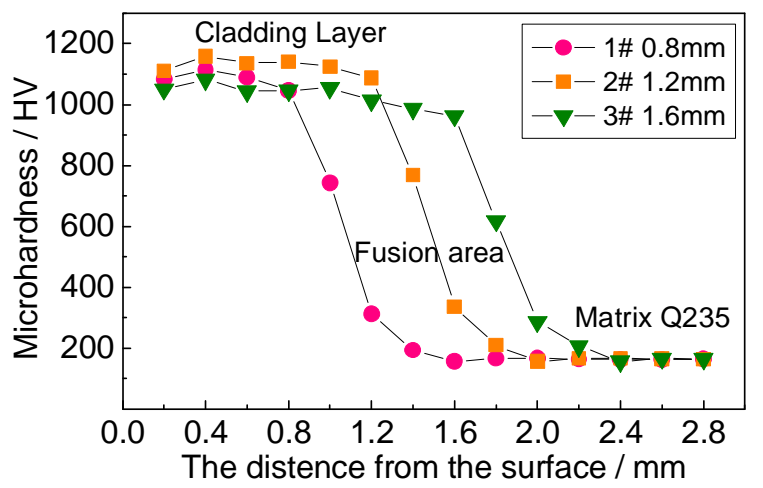

Fig.4 Microhardness distribution from surfacing to matrix

Wear resistance of composite coating. Fig. 5 is the comparison chart of wear capacity of the matrix, sample 1\#, 2\#, and 3\# surfacing layer under the same friction parameter. The figure shows that the wear volume of $2 \#$ was the lowest, that is the highest wear resistance, while 1\# secondly, and $3 \#$ thirdly. Those are 14.3 times, 13 times and 11.5 times than the wear resistance of the steel matrix respectively. The preset coating thickness of sample 2\# is appropriate, with strong binding force.

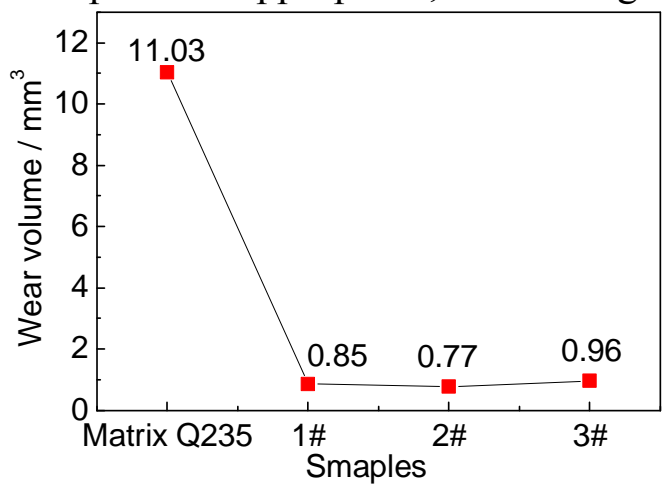

Fig.5 Comparison chart of wear volume

\section{Conclusions}

(1) Ti $(\mathrm{C}, \mathrm{N})$ reinforced nickel base powder coating was wear hardened by ultrasonic-assisted argon-arc clad injection technology on Q235 steel plate. By the acoustic cavitation, acoustic streaming and other secondary effect of high-energy ultrasound propagating in molten pool, to produce the composite coating with high hardness, good wear resistance, and corrosion resistance.

(2) A large number of $\mathrm{Ti}(\mathrm{C}, \mathrm{N})$ reinforced phase, needle like $\mathrm{TiC}$ and $(\mathrm{Fe}, \mathrm{Ni})_{23} \mathrm{C}_{6}$ phase, and larger sheet $\mathrm{Cr}_{23} \mathrm{C}_{6}$ and $\mathrm{Cr}_{7} \mathrm{C}_{3}$ phase mainly containing Fe distributed dispersively on the cladding layer, while the matrix composed of three elements for $\mathrm{C}, \mathrm{Fe}$, and $\mathrm{Ni}$ elements.

(3) When the thickness of the coating was $1.2 \mathrm{~mm}$, the appearance of cladding layer is better, the enhanced particles distributed uniformly, the hardness and wear resistance were the best, with good comprehensive performance.

\section{Acknowledgements}

Supported by the Open Project of Jiangsu Key Laboratory of Large Engineering Equipment Detection and Control (Grant No. JSKLEDC201308), the Science and Technology Project of Xuzhou (Grant No. KC14SM100), and sponsored by Qing Lan Project of University of Jiangsu Province in 2014.

\section{References}

[1] Wang Zhenting, Zheng Wei. Microstructure and wear resistance of in-situ synthesis Ti(C, N) -TiB2 particle reinforced Ni60A matrix composite coating by argon arc cladding [J]. Transactions of materials and heat treatment, 2011, 32(12):115-119. 
[2] Amirsadeghi A, Heydarzadeh S M. Comparison of the influence of molybdenum and chromium TIG surface alloying on the microstructure, hardness and wear resistance of ADI [J]. Journal of Materials Processing Technology, 2008, 201: 673-677.

[3] Yu-Chi Lin, Yong-Chwang Chen. Reinforcements affect mechanical properties and wear behaviors of WC clad layer by gas tungsten arc welding [J]. Materials and Design, 2013, 45: 6-14.

[4] Ning Zhang, Chen Hao, Jiang Xu. Microstructure and Property Study on Wear Resistant Composite Coating Produced By Ultrasonic-assisted Argon-Arc Clad Injection[J]. Advanced Materials Research, 2014, 1046: 58-61.

[5] Ning Zhang,Chunhong Zhang, Juli Li. Research of in-situ synthesis Ti(C、N)-WC particle reinforced Ni60A composite coating by argon arc cladding[J]. Journal of Xuzhou Istitute of Technology(Natural Sciences Edition), 2015, 30(1): 47-51.

[6] Dekun Zhang, Junjie Duan. On the Siding-rolling Friction and Wear Properties of Point Contact Friction Couple Between GCr15 Steel Ball and GCr15 Steel Disc[J]. Journal of Xuzhou Istitute of Technology(Natural Sciences Edition), 2014, 29 (4): 7-12. 